\title{
Modeling Regional Dynamics of Human-Rangifer Systems: a Framework for Comparative Analysis
}

\author{
Matthew Berman $^{1}$
}

\begin{abstract}
Theoretical models of interaction between wild and domestic reindeer (Rangifer tarandus; caribou in North America) can help explain observed social-ecological dynamics of arctic hunting and husbandry systems. Different modes of hunting and husbandry incorporate strategies to mitigate effects of differing patterns of environmental uncertainty. Simulations of simple models of harvested wild and domestic herds with density-dependent recruitment show that random environmental variation produces cycles and crashes in populations that would quickly stabilize at a steady state with nonrandom parameters. Different husbandry goals lead to radically different long-term domestic herd sizes. Wild and domestic herds are typically ecological competitors but social complements. Hypothesized differences in ecological competition and diverse human livelihoods are explored in dynamic social-ecological models in which domestic herds competitively interact with wild herds. These models generate a framework for considering issues in the evolution of Human-Rangifer Systems, such as state-subsidized herding and the use of domestic herds for transportation support in hunting systems. Issues considered include the role of geographic factors, markets for Rangifer products, state-subsidized herding, effects of changes in husbandry goals on fate of wild herds, and how environmental shocks, herd population cycles, and policy shifts might lead to system state changes. The models also suggest speculation on the role of geographic factors in the failure of reindeer husbandry to take hold in the North American Arctic. The analysis concludes with suggested empirical strategies for estimating parameters of the model for use in comparative studies across regions of the Arctic.
\end{abstract}

Key Words: caribou hunting; Rangifer tarandus; reindeer herding; social-ecological systems; system models

\section{INTRODUCTION}

Reindeer (Rangifer tarandus; caribou in North America) have played a prominent role in the history, culture, and material well-being of Arctic residents for thousands of years (Kofinas et al. 2000, Gordon 2003, Huntington and Fox 2005, Vitebsky 2005). The persistence and diversity of social-ecological systems involving Rangifer suggest a process of adaptation to changing conditions. Over the years, a number of scholars have formalized the relationships between people and animals in models of Human-Rangifer Systems (HRSs) (Paine 1964, Ingold 1980, Beach 1981, Krupnik 1993, Stammler 2005, Dwyer and Istomin 2008). Formal models aid the development of theory by strategically stripping away details characteristic of descriptive studies to generalize about underlying processes and suggest testable hypotheses about specific aspects of a system. The present paper contributes to this strand of literature by modeling adaptation to change as suggested by the historical record.

For the past three decades, Ingold's (1980) classic model of the HRS has served as the starting point for theoretical expositions. Ingold defined three basic human-Rangifer livelihood strategies: hunting and two forms of husbandrypastoralism and ranching (Fig. 1). Pastoralism and ranching differed not only with respect to the manner of herdingintensive vs. extensive herding - but also with respect to the hypothesized goal: transportation and possibly milk production vs. production of meat and hides. Ingold aligned
Fig. 1. Human-Rangifer modes of production. Source: Ingold (1980:4).

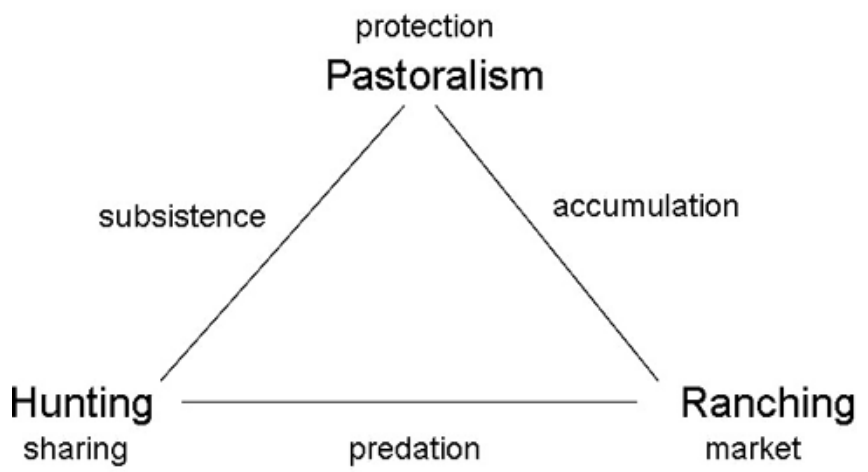

pastoralism with hunting among subsistence systems, in contrast to the market-based ranching mode.

Ingold (1980) hypothesized a directional process of evolution from hunting to pastoralism to ranching. Krupnik (1993) suggested that the spread of domestication of reindeer across Eurasia was a response to challenges to food security during climate-driven wild herd declines. Beach (1981) modeled how the transition from intensive to extensive herding occurred among Saami in Sweden. Although the empirical evidence 
Table 1. Key processes in human-Rangifer systems and presence in different system states. ("x" in a cell indicates a process typically a significant feature of the system; "(x)" in a cell indicates a process locally present but not prominent)

\begin{tabular}{|c|c|c|c|c|c|}
\hline & $\begin{array}{l}\text { Hunting- } \\
\text { intercepting }\end{array}$ & $\begin{array}{l}\text { Hunting-herd- } \\
\text { accompanying }\end{array}$ & $\begin{array}{l}\text { Pastoralism- } \\
\text { protecting }\end{array}$ & $\begin{array}{l}\text { Pastoralism- } \\
\text { accumulating }\end{array}$ & $\begin{array}{l}\text { Market production- } \\
\text { hunting or ranching }\end{array}$ \\
\hline Wild Rangifer availability & $\mathrm{x}$ & $\mathrm{x}$ & $(\mathrm{x})$ & & $(\mathrm{x})$ \\
\hline Hunting effort & $\mathrm{x}$ & $\mathrm{x}$ & $(\mathrm{x})$ & & $(\mathrm{x})$ \\
\hline Harvest sharing & $\mathrm{x}$ & $\mathrm{x}$ & $(\mathrm{x})$ & & \\
\hline Demographic change & $\mathrm{x}$ & $\mathrm{x}$ & $\mathrm{x}$ & $\mathrm{x}$ & \\
\hline Community mobility & & $\mathrm{x}$ & $\mathrm{x}$ & $\mathrm{x}$ & \\
\hline Herd control & & & $\mathrm{x}$ & $\mathrm{x}$ & $(\mathrm{x})$ \\
\hline Herd composition & & & $\mathrm{x}$ & $\mathrm{x}$ & $\mathrm{x}$ \\
\hline Milk production & & & $\mathrm{x}$ & $(\mathrm{x})$ & \\
\hline Slaughter & & & (x) & $\mathrm{x}$ & $\mathrm{x}$ \\
\hline Product markets & & & & & $\mathrm{x}$ \\
\hline Financial management & & & & & $\mathrm{x}$ \\
\hline
\end{tabular}

available at the time may have supported such a historical progression, transitions in postSoviet Russia (Krupnik 2000, Ulevadet and Klokov 2004) contradicted Ingold's hypothesis. Some former state-farm herders became intensive-herding pastoralists or tamed some animals for transportation while nomadically tending large herds; others became hunters of wild or mixed wild and feral reindeer (Ziker 2002, Stammler 2005, Dwyer and Istomin 2008). Modern state-sanctioned market hunting of wild Rangifer herds in contemporary Canada, Greenland, and Russia belies the proposition that hunting is strictly a subsistence activity.

Stammler (2005), noting how the modern historical record contradicted Ingold (1980), recast his archetypes as a set of adaptations to different social and ecological conditions. Except for Ingold (1980), models of the HRS in the literature generally address individual manifestations. The process of change from one mode to another is not well understood: specifically lacking is a mechanism that could predict how environmental change affects system dynamics and leads to different observed patterns. The remainder of this paper attempts to close this gap. First, we model adaptation to environmental conditions suggested by Stammler (2005) to generalize how the HRS, like other social-ecological systems, incorporates specific adaptations to mitigate uncertainty. Second, we model the dynamics of change in a way that could support empirical tests of hypotheses about growth, limits, or thresholds of stability and transitions to different states.

\section{HUMAN-RANGIFER SYSTEM STATES AND ADAPTATION TO ENVIRONMENTAL UNCERTAINTY}

Before discussing models of adaptation to environmental uncertainty, it is important to have a common understanding of HRS states and their characteristics. Social-ecological system states-specific patterns of social and ecological structure and function-are typically defined in terms of amounts of different ecological components, such as grass or livestock (Walker et al. 2004). Human-Rangifer system states, all of which involve the same ecological components, must be distinguished mainly by social processes and processes governing the relationships between people and animals.

\section{Key Processes in Human-Rangifer Systems}

Berman et al. (2004) defined rules for nine activities for an agent-based model of a modern Arctic caribou-hunting community. The nine activities modeled three key processes in the social-ecological system: hunting effort, harvest sharing, and community demographic change (Table 1). Ecological processes related to caribou population dynamics and distribution entered the model via scenarios for seasonal spatial Rangifer availability, based in part on output from a linked model of caribou population (Rangifer recruitment). Hunters in this mixed economy needed some cash income to operate modern technology that enabled them to mobilize hunting effort. Wage work provided the main source of cash, but also took time away from hunting caribou (Berman and Kofinas 2004). A herd-accompanying hunting system would add community mobility as a seventh process to those of the interception system (Table 1). Government-imposed compulsory schooling has probably relegated herdaccompanying hunting systems to the historical past.

Table 1 shows two processes common to all pastoral systems: herd control-protecting animals from predators, parasites and disease, and keeping animals together and moving them, and herd composition-selective breeding and decisions on desired herd size and characteristics. In Paine's (1964) classic analysis, herd control (herding) is a near-term decision, whereas herd composition (husbandry) takes a long-term view. Two other processes shown in Table 1 differ for the two pastoral systems: milk production and slaughter. Slaughterkilling selected animals to meet various husbandry objectives - may occur in the protecting mode of pastoralism, but would 
Fig. 2. Patterns of environmental uncertainty in a social-ecological system, along with associated mitigation strategies.

\section{Sharing: variation across households}

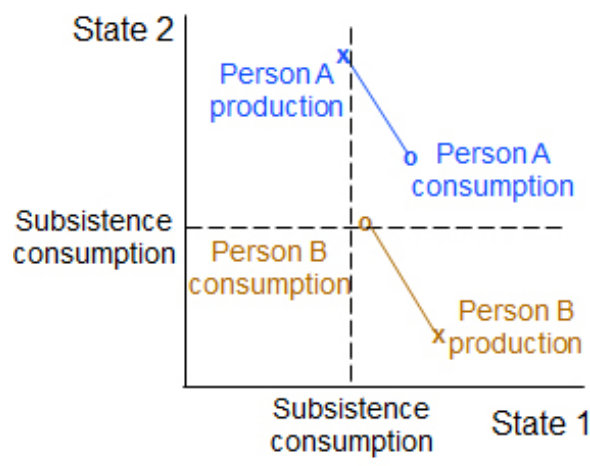

Moving: variation across places

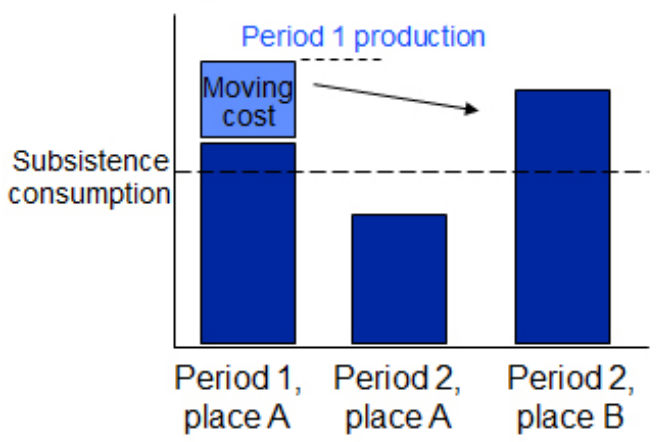

Storing: variation over time

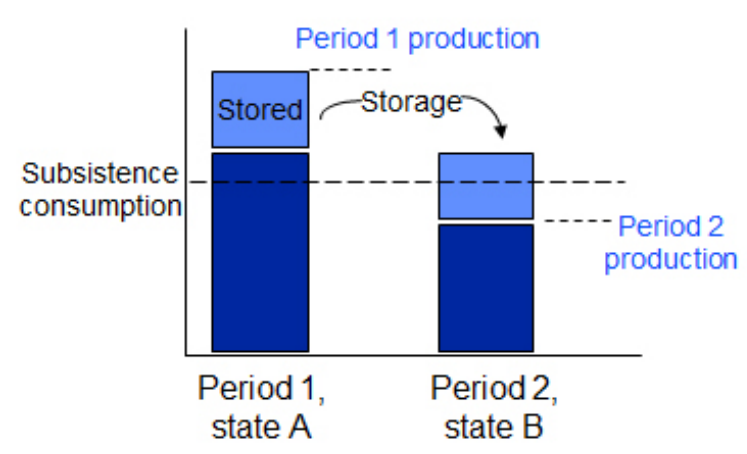

Fortifying: reduce exposure

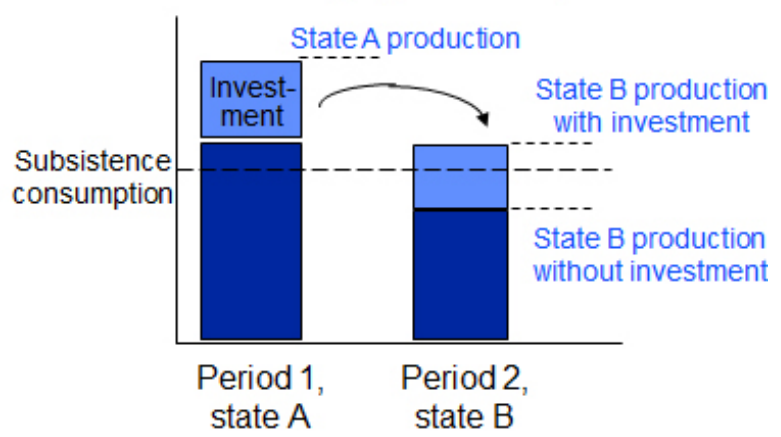

be secondary to hunting and fishing for food. The marketbased production state involves two additional processes associated with the sale of Rangifer products: markets and financial management.

\section{Adaptation to Environmental Uncertainty}

Neither the social nor ecological environment is static; both are subject to unpredictable events. A resilient HRS meets basic needs in bad as well as good times, accommodating environmental variability without loss of food security or other threat to survival of animals or people. Households may successfully reduce or eliminate the risk of critical consumption shortfalls using different mechanisms to pool uncertain production outcomes, depending on the specific pattern of environmental variability encountered in a place. They may attempt to pool production outcomes among households (share) or over time (store) in a given place. Households may also change locations (move) to diversify place-based risk. People may also undertake activities specifically designed to change the pattern of environmental risks (fortify): for example, constructing water management infrastructure to mitigate drought or flooding. Purchasing commercial insurance diversifies risk only if the insurance company is able to stay solvent by pooling uncertain outcomes across households, across places, and over time. Absent perfect insurance markets, people must take repeated sharing, storing, moving, and fortifying actions to mitigate environmental risks, which often become institutionalized in social relationships and ritual practices.

Figure 2 illustrates the four stylized patterns of risk pooling mentioned above. Sharing mitigates uncertainty across individuals in the same place; moving mitigates place-based outcomes; storing sets aside a portion of current production to hedge against future shortfalls; fortifying invests in environmental management to reduce future uncertainty. Each of these strategies may be visualized in terms of circulation (movement) or protection (husbandry) of the products of human effort (product) or the natural environment (nature, place). Sharing circulates product, whereas moving circulates nature or place. Storing protects product, whereas fortifying protects place or nature. Note that each of these four strategies 
requires some forward-looking or preparatory action to set aside a current surplus to preempt the surprise of a possible future shortfall. For example, sharing within culturally embedded systems of reciprocity provides individuals the opportunity to accumulate social credits through gifts (Sahlins 1972). Clearly these strategies become embedded in social relationships of modern economic systems as well as premodern stateless societies. Socialism institutionalizes centralized sharing. Market-based production involves trading current local production for credits against production elsewhere within the larger system. Market producers unable to store enough credits (accumulate wealth) to hedge against shortfalls may rely on mobility to mitigate risks. As wealth builds, industrial societies increasingly engage in public works or other fortifying efforts to reduce environmental risks.

Readers may note that this discussion of how social-ecological system states mitigate environmental uncertainty is generally consistent with human behavioral ecology (Borgerhoff Mulder 1991). However, as discussed below, history plays a role in resilience, creating a potential path-dependency typically absent from traditional human behavioral ecology approaches, such as optimal foraging theory (Smith 1983).

Wild Rangifer clearly rely on mobility as a principal adaptive strategy. Although human interactions with Rangifer must take this mobility into account, it would be simplistic to equate the movement of animals with movement of people as a strategy for mitigating environmental risk. Even before indigenous people in arctic North America were forced into permanent settlements, they rarely attempted to move with caribou herds during their seasonal migrations and instead placed seasonal settlements and camps in locations favorable for intercepting migrating herds (Burch 1991). When caribou were unavailable, people relied on other resources: marine mammals along the coast, fish, and other mammals such as moose (Alces alces). In these, as in other hunting cultures, people relied on sharing to smooth the lumpy nature of harvesting success, a characteristic noted by Ingold (see Fig. 1). Where people did rely predominantly on Rangifer year round, moving was a dominant feature of daily life (Burch 1991).

Domestication of reindeer for transport and milking represents a fortifying strategy to reduce the cost of moving and to provide a more predictable food supply. The behavioral ecology of Rangifer ensured that herders still have to move their herds. Dwyer and Istomin (2008) elaborated different models of mobility among Nenets herders. Ingold (1980) associated accumulation of larger numbers of reindeer-a storing strategy — with extensive herding and market production (ranching). Modern accounts of postSoviet reindeer herding (Habeck 2005, Stammler 2005, Vitebsky 2005, Klokov 2007, Dwyer and Istomin 2008), however, suggest that at least some pastoralists in the Russian Arctic practice intensive herding with herds of several thousand animals to meet husbandry objectives of market-oriented profit maximization, herd size maximization, or a combination of the two.

Because of the critical role that strategies to mitigate environmental uncertainty play in survival of the HRS, it makes sense to define HRS states in terms of these strategies. Addressing the observed variation in the portfolio of riskmitigating strategies, though, requires splitting Ingold's pastoral state into a subsistence-oriented "protecting" state, with small Rangifer herds providing transportation support and possibly dairy products to a mixed hunting, fishing, and trapping livelihood, and an "accumulating" state, with a husbandry goal of building larger herds.

Figure 3 summarizes the HRS hunting and pastoral states in terms of circulation or protection of product or nature. Meat cannot be stored over long periods of time without degrading, and luck of the hunt plays a big role in individual success. Consequently, harvest sharing effectively pools risk in hunting societies. Unlike hunters, herders can control the fate of individual reindeer. Consequently, exercising diligence with herd control and breeding animals rather than killing them ensures against future lean years. Awarding property rights over living animals allows an individual pastoralist to benefit from this socially beneficial behavior, providing an incentive to work hard and live frugally over many years to build up the herd. Sharing weakens that incentive by spreading the benefits to those who might not have worked and saved as much. Reduced sharing in husbandry, however, potentially leads to increased inequality, especially in the accumulating state.

Unlike subsistence hunting and husbandry, which produce a mix of household food and informal social credits, market activities generate cash income: a formal claim on production from the larger society. Commercial hunters and herders can store the uncertain stream of Rangifer profits in nonRangifer assets: basically outside the HRS itself. To the extent that Rangifer producers rely on this claim on national production to mitigate environmental risk, market-based production constitutes a fifth system state, as shown at the bottom of Fig. 3. Market hunting and Ingold's ranching type have similar consequences for risk mitigation, the main difference being the social issue of whether property rights to animals and land are considered divided or held in common (Ingold 1980:5). This fifth system state could also model Rangifer production in the Soviet-era state farm (sovkhoz), which forwarded its products to society at large in the planned economy in exchange for a share of national production.

The discussion of system states suggests some overall hypotheses about resilience and thresholds of change in HRSs and other social-ecological systems. System states embody a set of social responses for smoothing variability of outcomes of stable patterns of environmental uncertainty. When the pattern of uncertainty changes so that established strategies 
Fig. 3. Human-Rangifer system states. Each state relies on a different mix of strategies for mitigating environmental uncertainty. (Most prominent strategy for each state noted in boldface; less prominent strategies are grayed out.)
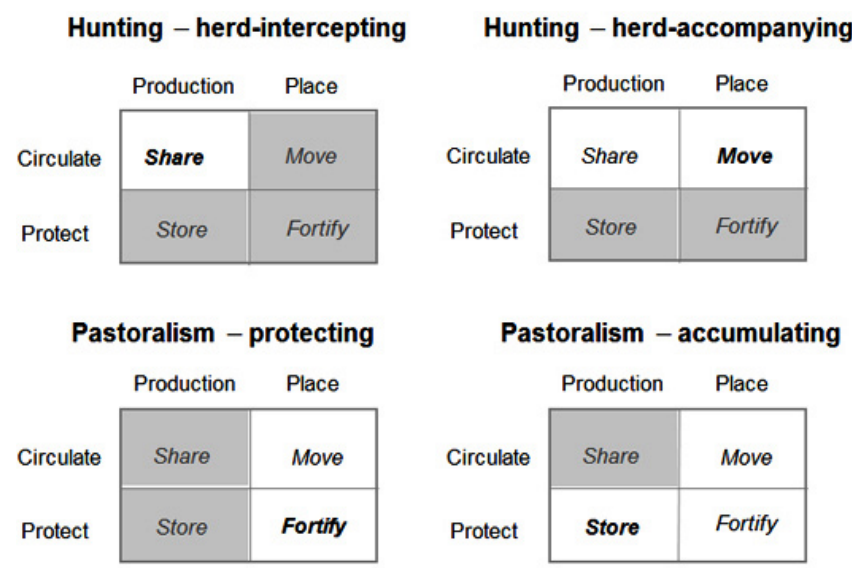

Market production - hunting or ranching

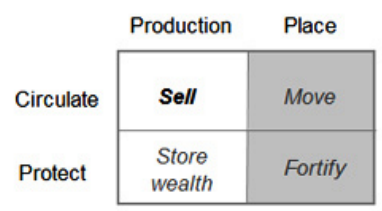

no longer reliably prevent critical food shortages or other risks to human life or well-being, new mitigation strategies are likely to emerge, resulting in a shift in the system state (Krupnik 1993).

\section{MODELING SOCIAL-ECOLOGICAL DYNAMICS}

Despite the diversity of historical and theoretical HRS states, the observed contemporary pattern shows pronounced regularities. In every Arctic region, one HRS state appears dominant: hunting-intercepting throughout North America and in parts of Siberia, pastoral-accumulating in Yamal, ranching in the European Arctic. In only a few places do hunting and herding states appear to coexist in the same region beyond small, isolated enclaves. The policy-driven demise of herd-accompanying hunting systems and the technologydriven retreat of pastoral systems supporting foraging livelihoods have simplified the HRS landscape. Interesting modeling questions remain concerning the dynamics of the remaining hunting and pastoral HRS states.

The main "state variables" for a model describing the status of the HRS in either a hunting or pastoral state would be wild and domestic Rangifer populations, which enable harvests to support the local Rangifer-dependent human population. The main processes determining the time path of those state variables would be wild and domestic Rangifer recruitment (excess of births over natural mortality) and harvest: the "control variables." Ecological forces largely determine recruitment, whereas social processes determine harvest. The other processes listed in Table 1 enter the model to the extent that they affect the control variables. First, we explore questions about resilience arising from simple dynamic models of hunting and husbandry systems. These questions are then explored further in models interacting hunting and herding systems.

Dynamics of Simple Random Density-Dependent Models Starting with a basic density-dependent dynamic model of a wild Rangifer herd, Rangifer population, $N_{t}$, changes from one year, $t$, to the next as a log-linear function of a maximum recruitment rate, $r$, limited by carrying capacity, $K$ :

$$
\frac{N_{t+1}}{N_{t}}=e^{r\left(1-N_{t} / K\right)}
$$

With a fixed human harvest, $h$, the herd population changes as follows:

$$
N_{t+1}=N_{t} e^{r\left(1-N_{t} / K\right)}-h_{t}
$$

Ecological variability enters the model as random variation in recruitment. Climate cycles such as the Arctic Oscillation and related North Atlantic Oscillation (Thompson and Wallace 1998, Thompson et al. 1999) tend to be multiyear events. Adverse grazing conditions may not only increase mortality but reduce pregnancy rates for cows, affecting the following year's calf production (Russell et al. 2005). There is reason, therefore, to expect that random variation in the recruitment parameter, $r$, would be autocorrelated over time:

$$
r=r_{0}+u_{t}: \quad u_{t}=\rho u_{t-1}+\varepsilon
$$

where $\varepsilon$ is normally distributed with a mean of zero and a variance proportional to $r_{0}$. Longer term climatic shifts or ecological change could also cause carrying capacity, $K$, to increase or decrease, but that possibility will be ignored for now.

Harvests could also vary randomly. For example, variation in migration routes could affect accessibility to hunters in a herdintercepting system (Berman and Kofinas 2004):

$$
h_{t}=h_{0}+\delta
$$


Fig. 4. Dynamics of a hunted wild Rangifer population, $\mathrm{N}$ (left axis), with autocorrelated random, densitydependent recruitment $r$ (right axis). In this example, $\mathrm{K}=250$, mean $\mathrm{r}=12 \%$ of $\mathrm{N}$, with coefficient of variation $=0.3$ and autocorrelation $\rho=0.7$; mean harvest $=8.25$, with coefficient of variation $=0.5$ and upper limit $10 \%$ of $\mathrm{N}$. Right panel illustrates nonrandom density-dependent recruitment with $\mathrm{r}=8.25$ and harvest $=8.25$.

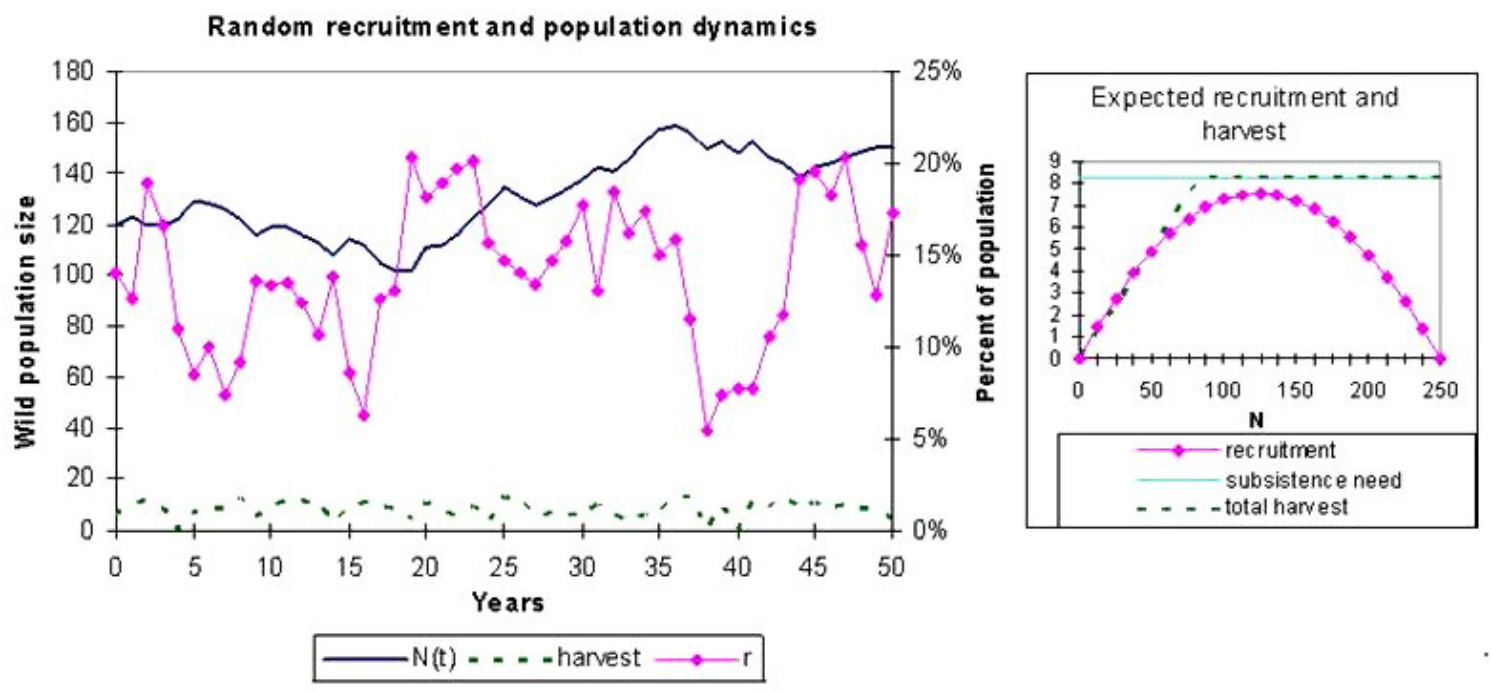

where $\delta$ is normally distributed with a zero mean and a variance independent of $\varepsilon$ and proportional to $h_{0}$. Figure 4 illustrates a 50 -yr simulation of the herd population, $N_{t}$, under the assumption of autocorrelated random recruitment and randomly varying harvest given by equations (1) through (4). This example was produced with a spreadsheet model, assuming $h_{0}$ constant at $7 \%$ of the initial $N$ at $t=0(3.3 \%$ of $K$ ). The simulation also assumes a harvest management regime that limits harvest to no more than $10 \%$ of $N$. The curves on the right side of the figure show how harvest and densitydependent recruitment vary with population if $r$ and $h$ were fixed at their mean rates instead of varying randomly. With random harvest at its mean level, $h_{0}$, the harvest limit takes effect when $N$ falls below 83 .

With the autocorrelated random recruitment example in Fig. 4, herd size fluctuates between 100 and 160, never remotely approaching the theoretical carrying capacity of 250 that a zero-variance, zero-harvest simulation would reach after about 10 yr. The simple social-ecological model generates cycles similar to those observed in wild populations (see Gunn 2003). Figure 4 illustrates only one possible outcome from simulating the spreadsheet model through time. Although each simulation generates a different dynamic path of the system, repeated iterations with the same parameters show that population overall typically remains above 100 through the 50 -yr horizon. The harvest ceiling seems to make the system resilient to the modeled variability. Such a result is somewhat surprising, given that the maximum sustainable harvest occurs at $N=125$ and $h=7.5$-substantially below $h_{0}$ and the $10 \%$ harvest ceiling-when recruitment and harvest are nonrandom. However, raising $h_{0}$ from 8.25 to 10 makes a population crash virtually certain, even with the $10 \%$ harvest ceiling.

One might expect climate variation to cause a domestic Rangifer population to express the same autocorrelated random recruitment as a wild population, although husbandry may allow the mean of the recruitment parameter, $r$, to rise and its variation decline. Harvest could also be better managed, so that there should be little unplanned variation over time. Differing local husbandry objectives could lead to different decision rules for the harvest rate, generating potentially different dynamic paths for Rangifer population. Figure 5 illustrates the effect on the size of a domestic herd under diverse husbandry objectives. The figure uses the same spreadsheet simulation model that generated Fig. 4, but with parameter values representative of a domestic herd. In the example depicted in the figure, there is a subsistence harvest level of 3 that acts as a harvest floor, and a limit on commercial harvest of five additional units, due to hypothetically limited local processing capacity.

The higher and less variable recruitment parameter assumed in the simulations shown in Fig. 5 allows the pastoral system state to support larger sustainable harvests than the hunting 
Fig. 5.. Dynamics of a domestic Rangifer population (N) with autocorrelated random, density-dependent recruitment parameter $\mathrm{r}$ (right axis) under harvest rules representing different husbandry objectives (N1: target harvest $=7 \%$ of N, N2: maximum herd growth, N3: maximum sustained yield, N4 = target herd size of 20). In this example, $\mathrm{K}=100$, mean $\mathrm{r}=25 \%$, with coefficient of variation $=0.15$ and $\rho=0.3$; subsistence harvest $=3$, and upper limit of 5 on non-subsistence harvest. Right panel illustrates nonrandom density-dependent recruitment with the same parameter values.

\section{Random recruitment and population dynamics}

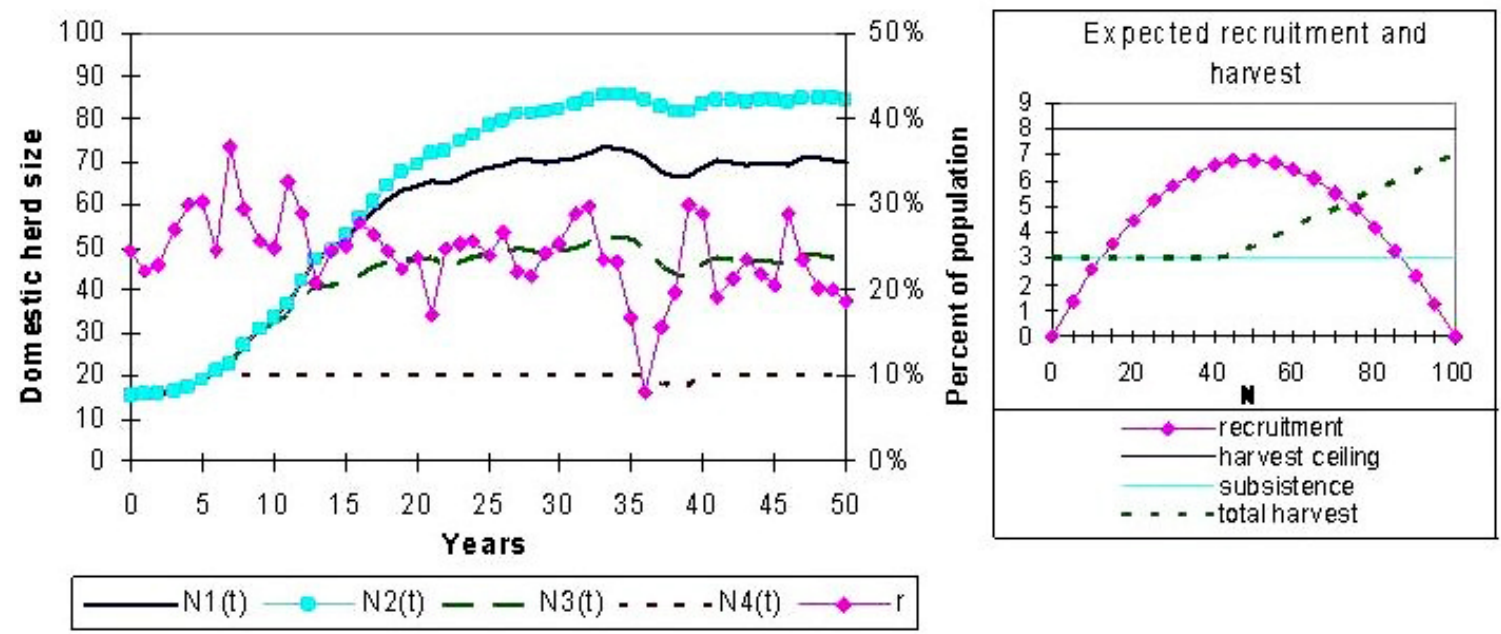

system state, along with considerably less variation in the Rangifer population. As the figure shows, harvest rules representing different husbandry objectives cause the herd to stabilize at different population levels. A strategy limiting harvest to the subsistence level to maximize herd growth pushes $N$ to about $85 \%$ of carrying capacity, $K$. Population stabilizes at around $50 \%$ of $K$ for a strategy of maximum sustained yield, which sets the harvest rate to $r / 2$. This strategy is equivalent, assuming constant incremental costs, to a strategy of maximum profit at a zero discount rate. Higher discount rates would reduce final herd size somewhat. Between the long-term population that maximizes herd growth and that which maximizes harvest lies one derived from a target harvest of $7 \%$ of the herd. The lowest line in Fig. 5 follows a strategy of maintaining a target herd level just sufficient to meet the subsistence consumption level of 3 , selling or slaughtering any surplus animals. Once the herd size reaches the target level of 20 , the simulation shows that randomly varying recruitment rarely fails to meet or exceed the subsistence harvest need even with the relatively low herd size.

\section{Interaction of Wild and Domestic Herds}

Figures 4 and 5 illustrate baseline dynamics of wild and domestic populations in isolation. Where they interact, wild and domestic herds are ecological competitors. They consume the same forage. Wild herds are vulnerable to overgrazing and trampling of vegetation by large concentrations of domestic animals. Domestic animals pick up parasites and diseases from wild herds and vice versa. Domestic animals that are not closely controlled may run off and be absorbed by large wild herds migrating through herding areas. On the other hand, husbandry and hunting are social complements. Domestic animals may provide transportation for hunters. Wild and domestic herds are substitutes for meeting subsistence needs; domestic herds kept for food may reduce hunting pressurehuman predation - on wild herds. Due to economies of scale in developing market institutions, commercial hunting of large wild herds may foster creation of processing infrastructure that allows husbandry to cross a threshold for commercial viability.

Consider two interacting wild and domestic populations, each with density-dependent recruitment with respect to their own populations and the regional ecological carrying capacity, $K$. Continuing with the symbol $N$ to represent the wild population, but now using $D$ to represent the domestic population, a general random, density-dependent relationship for wild and domestic population changes over time could be expressed as:

$$
\begin{gathered}
\Delta N / \Delta t=f(N, D, K)+u_{t}: f(0,0, K)=0, \\
f(K, 0, K)=0, f(N, 0, K)>0(0<N<K)
\end{gathered}
$$




$$
\begin{aligned}
& \Delta D / \Delta t=g(N, D, K)+v_{t}: g(0,0, K)=0, \\
& g(0, K, K)=0, g(0, D, K)>0(0<D<K)
\end{aligned}
$$

where $u_{t}$ and $v_{t}$ represent random terms with a zero mean. The density-dependent property of functions $f$ and $g$ implies that the partial derivatives with respect to their own populations would be positive and decreasing for populations less than $K$. If we assume the presence of a domestic population reduces the recruitment rate for wild herds and vice versa, the partial derivative of $f$ with respect to $D$, and the partial derivative of $g$ with respect to $N$ would both be negative.

The properties of Eq. (5) imply that for a given $K$ and domestic population, $D$, there is a unique level of the wild population $(N<K)$ for which the expected value of $\Delta N / \Delta t=0$. This level, represented by the symbol, $N^{S}$, denotes an expected steadystate wild population as a function of $K$ and $D$. Similarly, the properties of Eq. (6) imply that, for a given $K$ and wild population, $N$, there is an expected steady-state domestic Rangifer population, $D^{S}$, that yields an expected $\Delta D / \Delta t=0$.

The interaction of wild and domestic herds modeled in Eqs. (5) and (6) makes no assumption about whether competitive impacts of one herd on the other are linear or symmetrical. Differential effects of ecological competition suggest asymmetrical and nonlinear interactions of domestic and wild stocks. For example, when populations grow, asymmetric effects occur if wild herds are better able to disperse to avoid overgrazing and trampling forage than domestic herds, and to move long distances across difficult terrain to exploit summer and winter ranges. Domestic animals may run off with wild herds, while high-density domestic herding exacerbates parasite and disease issues. However, husbandry practices such as selective breeding, managed age-sex distribution, protection from predators, and veterinary medicine may offset the disadvantages of high domestic populations.

The processes through which regional presence of wild Rangifer might affect domestic Rangifer suggest nonlinear effects on the expected steady-state domestic population, $D^{S}$. At low wild numbers, domestic herds rarely encounter large groups of wild animals. The effect on the expected change in domestic population is small. As wild herds grow, the conflicts intensify, but reindeer herders can move their animals away from migrating wild herds, mitigating the effects somewhat. If wild herds grow too large, however, there becomes a point where herders cannot effectively keep their animals away from wild herds, and begin to lose control of them. At some level of wild Rangifer, husbandry is no longer feasible, and the steady-state domestic population drops to zero. A function representing the expected steady-state domestic population $D^{S}$ that is consistent with Eq. (6) and with the properties described in the previous scenario would be:

$$
\begin{aligned}
& D^{S}=D^{S}(N, K): \quad \partial D^{S} / \partial N<0, \\
& \partial^{2} D^{S} / \partial N^{2} \leq 0, \partial D^{S} / \partial K>0
\end{aligned}
$$

The effect of increasing numbers of domestic animals on the expected steady-state wild herd is also likely to be nonlinear, but might differ somewhat. With small domestic herds, herders seeking to avoid contact with wild herds may cause few effects on them. When the domestic population grows further, domestic animals begin to consume significant amounts of forage and increase parasite vectors. The steady-state wild population drops, but not as much as the increase in domestic numbers, because herders' efforts to concentrate domestic animals in areas where they may more easily be controlled to keep them away from wild herds promotes ecological specialization. At some husbandry population, forage becomes limited, and even a small harvest may extirpate the reduced wild population. A function representing expected steady-state wild population $N^{S}$ that is consistent with Eq. (5) and has the properties just described might be:

$$
\begin{aligned}
& N^{S}=N^{S}(D, K): \quad \partial N^{S} / \partial D<0, \\
& \partial^{2} N^{S} / \partial D^{2} \leq 0, \partial N^{S} / \partial K>0
\end{aligned}
$$

Figure 6 illustrates the expected steady-state relationships for $N^{S}$ and $D_{S}$ described in Eqs. (7) and (8), shown with wild population on the horizontal axis and domestic population on the vertical axis. The maximum domestic herd population above which no wild herds persist in the steady state is denoted by the point $D^{*}$ in the vertical axis in the left panel of the figure. A similar point $N^{*}$ on the right panel represents the maximum wild herd size consistent with any level of domestic herding.

The curves in Fig. 6 represent expected steady-state populations; random variation in recruitment assures that the steady state is always being perturbed. Arrows in the figure show that the expected change in population is negative for combined levels of $D$ and $N$ that exceed the steady-state levels, and positive for $D$ and $N$ that fall short of the steady-state levels. Ecological change that causes $K$ to increase or decrease would shift both curves out or in, respectively. Social change could also cause $N^{S}$ and $D^{S}$ to shift. For example, changes in subsistence harvest or harvest management would change recruitment dynamics for wild herds. The simulations of domestic populations shown in Fig. 5 show that a change in harvest rules associated with changing husbandry objectives would cause the domestic population to stabilize at different levels. 
Fig. 6. Simple density-dependent models of interaction of wild (N) and domestic (D) herds. Solid line shows potential equilibrium solutions. Arrows show direction of change from positions out of equilibrium $(\mathrm{N}=$ horizontal, $\mathrm{D}=$ vertical)
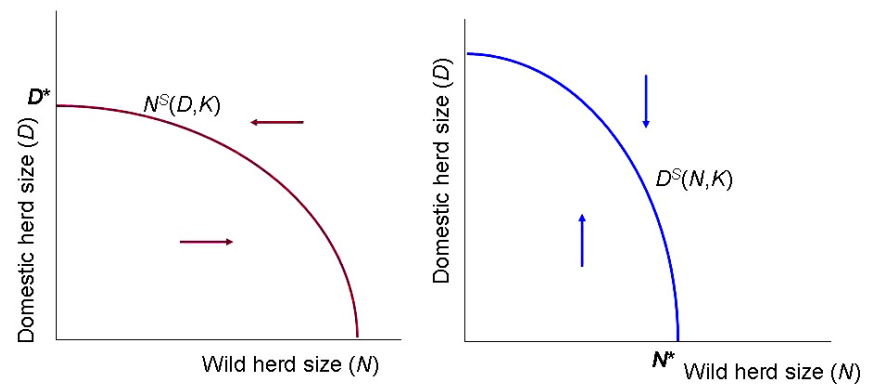

To model the competitive dynamics of wild and domestic populations, we combine the expected steady-state relationships for wild and domestic herds. Asymmetric competitive effects of domestic and wild herds imply that the effect of domestic population on $N^{S}$ differs from the effect of wild population on $D^{S}$. Figures 7, 8, and 9 illustrate potential dynamic interaction suggested by the nonlinear asymmetrical expected steady-state relationships depicted in Fig. 6. In interpreting these figures, one should keep in mind that wild herds cannot coexist with reindeer husbandry if the expected steady-state domestic population with no wild herds present exceeds the domestic population that drives wild herds to local extinction $\left(D^{S}(0, K)>D^{*}\right)$. Husbandry is likewise infeasible if $N^{S}(0, K)>N^{*}$.

Fig. 7. Dynamics of harvested wild and domestic Rangifer populations with autocorrelated random, simple combined density-dependent recruitment (r). In this example, $K=100$, wild and domestic $r, v r$, and $\rho$ are the same, respectively, as in Figs. 4 and 5, and correlation of 0.45 for wild and domestic random $r$.
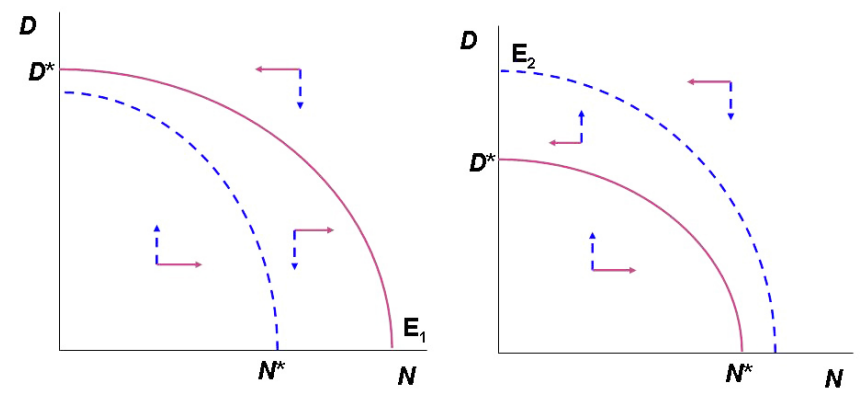

Fig. 8. More complex density-dependent models of interaction: domestic herds in competition with wild herds. Solid line shows stable population level for domestic herds given wild herd size. Arrows show direction of movement for population levels not on the line.

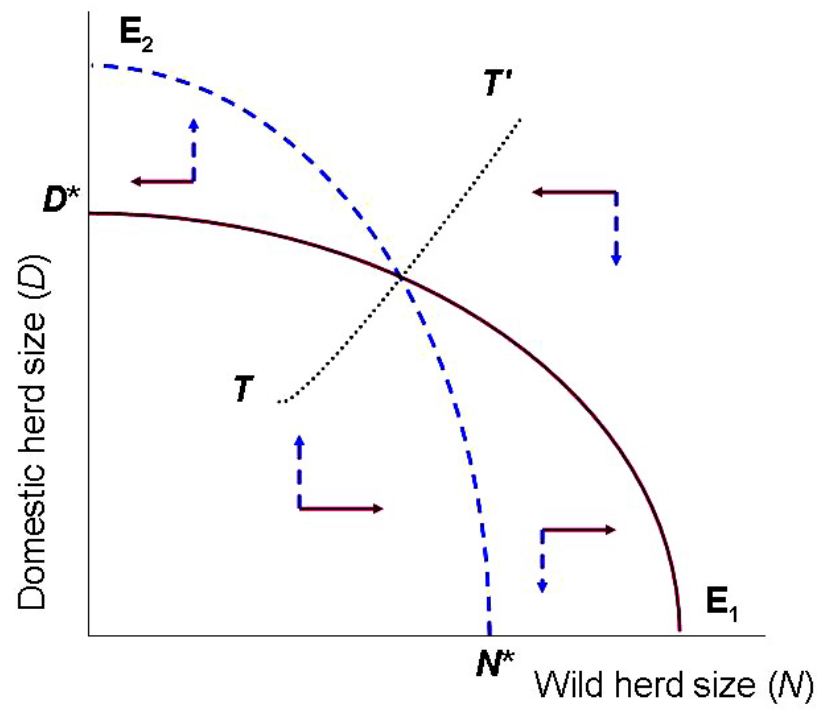

Fig. 9. More complex density-dependent models of interaction: wild herds in competition with domestic herds. Solid line shows stable population level for wild herds, given domestic herd size. Arrows show direction of movement for population levels not on the line.
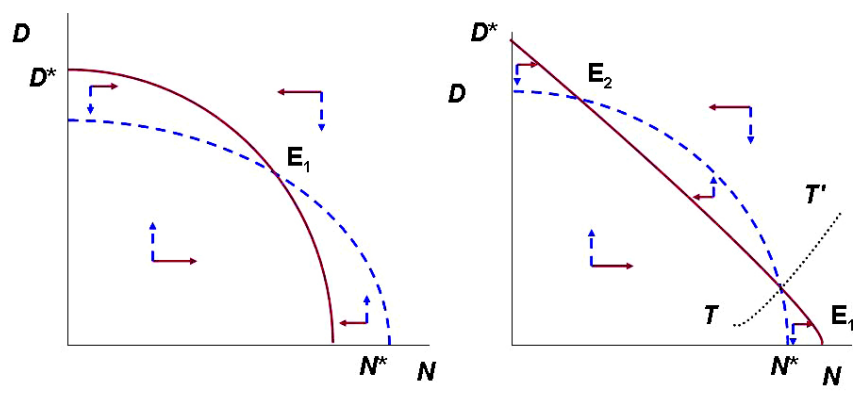

In Fig. 7, only one HRS state is ever feasible in the long run. In the left panel, the expected steady-state wild population lies above that of the domestic population for all combinations of $N$ and $D$, meaning that only the wild state is feasible (equilibrium E1). In the right panel, the expected steady-state domestic population always lies above that of the wild 
population, suggesting extirpation of wild herds once herding becomes established (point E2).

In Fig. 8, the competitive interaction produces two potential stable states: one with no domestic herds (E1) and one with high domestic herd levels and a no wild herds (E2). Which state occurs depends on whether the populations of wild and domestic herds align to the right or to the left of the statechange threshold TT'. If they lie to the right of the line, domestic herding will collapse; if they lie to the left, domestic herding will move to a dominant position. A single environmental shock such as a few years of adverse weather would not likely be sufficient by itself to cause states to shift. However, a large shock accompanied by a permanent shiftin climate, ecology, or the political economy - that displaces the threshold line could push a seemingly stable system past the threshold and cause a transition to a new state.

Figure 9 illustrates the conditions required for the system to produce feasible states maintaining both wild and domestic herds. The left panel shows a case where the system moves to coexistence at point E1. In the right panel, configurations of wild and domestic populations below and to the left of transition threshold TT" result in only wild Rangifer (point E1); configurations above and to the right of TT" lead to coexistence at point E2. As the figure illustrates, these outcomes require an improbable assumption: namely that domestic and wild herds be complements in at least some significant portion of the ecologically possible range of combined populations.

\section{DISCUSSION}

One finding of the analysis of herd dynamics is that under well-behaved relationships for steady-state trade-offs of wild and domestic populations, the size of one population in the absence of the other, relative to the size the population that eliminates the other population, predicts whether wild and domestic herds can coexist. If the domestic population with no wild herds present exceeds the domestic population that drives wild herds extinct, typically only domestic herds will be present. Similarly if the wild population with no domestic herds present is greater than the wild population that makes husbandry nonviable, then husbandry will fail. If both these conditions occur, then state changes from hunting to herding and vice versa are possible. Another finding is that different husbandry goals lead to radically different long-term domestic herd sizes. Social, economic, or political change favoring a shift in husbandry goals could cause large changes in equilibrium herd sizes, leading potentially to extinction or recovery of wild herds.

Models are useful tools for asking to what extent geography and history drive observed system states by shaping environmental risks and opportunities for adaptation. The dynamic model of competitive interaction of wild and domestic herds illustrates general principles. Applying it to a particular region could predict thresholds of change if one could obtain estimates of the parameters of the steady-state functions, $D^{S}$ and $N^{S}$, along with some understanding of the pattern of environmental instability that determines how far wild and domestic populations typically get pushed away from the steady-state levels. Although some important determinants of the parameters are social and political, others are geographic, and have changed little over the historical existence of HRSs.

\section{Geographic Factors Affecting Viability of Husbandry}

Domestic as well as wild Rangifer respond to the same drivers, whether or not their effects are mitigated by human effort. These conditions include environmental conditions such as forage quality, insects and disease, snow and ice, and physical barriers affecting the energetics of moving across the landscape, such as between the summer and winter ranges. Social factors-the dependent human population's food needs, availability of alternative resources and livelihoods, markets for Rangifer products, responsiveness of institutions of governance-do not directly depend on whether Rangifer harvests come from wild or domestic stocks. The primary difference in the system processes is the extent that Rangifer manage their own activities-moving between summer and winter ranges on their own time schedule, selecting habitat, avoiding predators, reproducing, etc. - or that human agents intervene to manage these activities.

Table 2 summarizes a set of geographic factors that might inhibit active Rangifer management and serve as natural barriers to domestication. Although these features are present in some form throughout the Arctic, there is clear variation in the extent to which they pose impediments to husbandry. The table illustrates the magnitude of each of these factors for eight regions in North America, including Greenland, and seven regions of Eurasia, running from west to east across the Arctic. Locally complex terrain in the Canadian Shield region and along the rugged coastline of the Arctic islands and Greenland challenges herd control, especially during long migrations. These conditions are largely absent from the Eurasian Arctic, with the exception of the west coast of Norway and the Bering Strait area of Chukotka.

Prominent barriers to movement-high-relief mountain ranges, steep canyons, and large water crossings between summer and winter ranges-occur in western arctic North America, as well as in portions of Nunavut and Greenland. Although Siberia contains numerous mountainous regions, Rangifer typically do not have to cross them to move between summer and winter pastures, because the tree line is generally much closer to the coast than in much of the North American Arctic. Proximity of the tree line to the coast affects the distance that reindeer herders have to travel during seasonal movements between summer and winter pastures. For this reason, Ingold (1980) speculated that transition to pastoralism started among hunters foraging along the tree line. 
Table 2. Physical and ecological impediments to reindeer herding in various Arctic regions

\begin{tabular}{|c|c|c|c|c|c|c|}
\hline \multirow[b]{2}{*}{ Region } & \multicolumn{2}{|c|}{ Physical geography } & \multicolumn{3}{|c|}{ Ecological geography } & \multirow[b]{2}{*}{$\begin{array}{c}\text { Total number of } \\
\text { physical and } \\
\text { ecological barriers }\end{array}$} \\
\hline & $\begin{array}{c}\text { Locally complex } \\
\text { terrain }\end{array}$ & $\begin{array}{l}\text { Barriers to } \\
\text { movement }\end{array}$ & $\begin{array}{l}\text { Tree line far } \\
\text { from coast }\end{array}$ & $\begin{array}{r}\text { Alternative } \\
\text { traditional } \\
\text { livelihoods } \\
\end{array}$ & $\begin{array}{c}\text { Large wild } \\
\text { Rangifer herds }\end{array}$ & \\
\hline Seward Peninsula & & & & $\mathrm{x}$ & & 1 \\
\hline Northwest Alaska & & & $\mathrm{x}$ & $\mathrm{x}$ & $\mathrm{x}$ & 3 \\
\hline Porcupine Region & & $\mathrm{x}$ & $\mathrm{x}$ & & $\mathrm{x}$ & 3 \\
\hline McKenzie Region & & $\mathrm{x}$ & & $\mathrm{x}$ & & 2 \\
\hline Nunavut Barrens & $\mathrm{x}$ & & $\mathrm{x}$ & & $\mathrm{x}$ & 3 \\
\hline Nunavut Islands & $\mathrm{x}$ & $\mathrm{x}$ & $\mathrm{x}$ & $\mathrm{x}$ & & 4 \\
\hline Nunavik, Quebec & $\mathrm{x}$ & & $\mathrm{x}$ & & $\mathrm{x}$ & 3 \\
\hline Greenland & $\mathrm{x}$ & $\mathrm{x}$ & $\mathrm{x}$ & $\mathrm{x}$ & & 4 \\
\hline Fennoscandia & & & & $\mathrm{x}$ & & 1 \\
\hline Kola Peninsula & & & & & & 0 \\
\hline Komi-Nenets Region & & & & & & 0 \\
\hline Yamal Peninsula & & & $\mathrm{x}$ & & & 1 \\
\hline Taimyr AO & & & $\mathrm{x}$ & & $\mathrm{x}$ & 2 \\
\hline Sakha Republic & & & & & $\mathrm{x}$ & 1 \\
\hline Chukotka AO & & & & $\mathrm{x}$ & & 1 \\
\hline
\end{tabular}

An ecological factor in Table 2 that might discourage husbandry is the concentration of wild Rangifer in large migratory herds in excess of 100,000 animals sharing a common calving area. Large wild herds could discourage herding both because their large size makes food security less an issue for hunting communities and because avoiding contact with domestic animals becomes more challenging during the high end of population fluctuations. Alternative livelihoods such as abundant accessible marine mammals or fish such as salmon could reduce dependence on Rangifer and require a high temporary time commitment that would compete with the constant effort required to control domestic herds.

\section{Implications for Human-Rangifer System Resilience}

Combining findings from models of strategies to mitigate environmental uncertainty with findings from dynamic models of interacting wild and domestic populations suggests lessons for HRS vulnerability and resilience. Although resilience and vulnerability have been used in many different ways and are sometimes conflated (Adger 2006, Folke 2006, Jansen and Ostrom 2006), we follow Turner et al. (2003), who formally defined vulnerability in terms of exposure to environmental risks, sensitivity to that exposure, and capacity to adapt to avoid harmful effects (see also Nelson et al. 2007). Resilience refers to the capacity of a system to accommodate external forcing or shocks without a major change to structure and function (Gunderson and Holling 2002). For modeling human-Rangifer dynamics, resilience best defines a property of a complete system, with vulnerability characterizing individuals, households, or communities within that system.
To maintain resilience, the HRS must both mitigate environmental uncertainty to minimize vulnerability of households to food insecurity, and remain ecologically viable, including under competition with other Rangifer. We noted that different modes of hunting and husbandry incorporate strategies to mitigate effects of differing patterns of environmental uncertainty. This implies a limit to resilience if a shift in environmental conditions changes the pattern of uncertainty to the extent that food security is compromised under the established mode. For example, climate-driven ecological change could reduce local carrying capacity. Changes in markets, state subsidies, or policies governing harvest can likewise make established Rangifer livelihoods nonviable. If a new HRS mode under these environmental conditions would allow food security to be regained, transition to a new system state is possible.

\section{Role of Economic and Political Factors}

Although biophysical influences may have played a large role in determining historical HRS states, economic and political forces may be more important drivers of modern systems. Modern Arctic states have curtailed movement across national borders and forced settlement and schooling of nomadic peoples. Resource development created new livelihoods, but also encroached on Rangifer habitat and erected new barriers to movement (Forbes et al. 2009). The history of government intervention in Arctic communities lies outside the scope of this paper. However, two modern drivers - transportation technology and markets-may play a critical role in the dynamics and potential resilience of modern HRSs. 
Introduction of mechanized off-road transportation, especially snow machines, greatly facilitated Rangifer herding and helped residents of permanent villages continue hunting traditions. In North America, state funding of public service employment and transfers that provided cash income have been critical to maintaining livelihoods based on living off the land while meeting the requirements of settled life (Berman et al. 2004). In Soviet Russia, state farms directly subsidized transporting herders in shifts between communities and herds in helicopters. The collapse of the Soviet economy in the early 1990s abruptly curtailed these transportation subsidies.

As suggested by Fig. 8, large shocks combined with a permanent shift - in climate, ecology, or the political economy -might be sufficient to push a seemingly stable system past the threshold line to cause a shift to a new state. Much as Krupnik (1993) hypothesized that climate change leading to food insecurity acted as a catalyst for the introduction of herding in medieval Eurasia, curtailed state subsidies in 1990s Russia would have dramatically reduced social carrying capacity, $K$, for domestic herds in areas without access to large regional markets. Such a change could lead either to an immediate change in state, as in Chukotka, or to unstable competition from wild herds responding to favorable environmental conditions, as in the Taimyr region (Ziker 2002).

The fate of herding systems in postSoviet Russia provides a window into resilience of HRSs globally. Although organizational structure varies locally, husbandry has generally continued or intensified in regions west of the Yenisei River, and declined or transitioned to a hunting state in the East (Klokov 2007). Markets for reindeer products appear to be a principal driver for that pattern.

Reindeer meat is traded globally; however, most market sales are local and regional, as only small amounts move to international markets outside Fennoscandia. Humphries (2007) reported 2005 carcass weight prices ranging from $\$ 1.50$ to $\$ 2.25$ per kg in North America, Greenland, and Scandinavia, depending on the quality. Meat and meat byproducts provided at least $80 \%$ of the value, with the remainder in antlers and hides. Regional prices in arctic Russian industrial centers were roughly similar to Western prices for products of comparable quality (Konstantin Klokov, personal communication, 6 December 2007). The only wild meat sold in global markets recently appears to come from Canada's Nunavut Territory. Commercial harvests of wild and domestic herds compete in regional markets in Greenland and in Taimyr and Sakha, Russia. (Alaska prohibits commercial sale of wild Rangifer.) The remoteness of the Arctic from population centers and resulting high cost of transportation explains why so little Rangifer meat finds its way into global markets. In Russia's western Arctic, the industrial cities of Norilsk, Vorkuta, and Murmansk, and growing oil and gas support populations in the Yamal Peninsula provide large regional markets close to herding areas. It is in these regions that herding continues to flourish. To the east, Russian regional markets are smaller and more remote from herding areas.

Physical and ecological geography create HRS drivers that typically change very slowly, if at all, whereas economic and political drivers can change abruptly and unpredictably. The Russian experience suggests that HRS states that may appear stable over decades or centuries may shift quickly under the right set of conditions.

\section{Speculation: Geographic Drivers of Human-Rangifer System History}

Røed et al. (2008) found that domestic reindeer currently present in different regions of Eurasia are genetically more similar to one or more local wild stocks than to either domestic or wild reindeer in other regions. This evidence suggests multiple separate instances of domestication in different regions. Nevertheless, there is no evidence that domestication ever took hold in North America before European contact. Repeated attempts to introduce domestic reindeer in the late 19th and 20th Centuries also failed to produce self-sustaining husbandry, even among herd-accompanying groups.

The pronounced difference between North America and Eurasia in geographic impediments to reindeer herding support speculation about their role in the failure of husbandry to take hold in the North American Arctic. In North America before European contact, one could explain the observed prevalence of herd-interception vs. herd-accompanying hunting systems through a combination of physical and ecological factors. Most important is the availability of alternative livelihood strategies. Inuit in Northwest Alaska moved to the coast during summer, and could survive on marine resources year round when caribou were scarce. In contrast, the Chipewyan had no alternative resource on a large scale (Burch 1980, 1991). However, the high terrain complexity of the Canadian Shield throughout the eastern half of North America provides a formidable obstacle to herd control.

\section{CONCLUSION}

This exploratory modeling exercise of Rangifer hunting and herding systems has developed theoretical foundations of differing system states, and discussed aspects of HRS dynamics in models that competitively interact domestic with wild herds. The simple models developed here illustrate what assumptions about drivers and responses of key processes produce resilient or unstable time paths of system state variables. The assumptions of autocorrelated random recruitment (likely with climate variation), combined with randomly varying harvest (likely with herd-intercepting hunting systems) appear to be sufficient by themselves to produce large cycles in wild Rangifer populations. If the 
population response of wild Rangifer differs from the response of husbanded animals to the same set of drivers-and there is no reason to expect that they would be the same-then domestic and wild Rangifer are unlikely to coexist in the same region in the long run. Under reasonable assumptions, competition for shared space between hunted and husbanded herds can lead to collapse and abrupt transition of either system. The greater the uncertainty in drivers, whether climate, political, or economic, the greater the chance of abrupt state changes.

The models described here are quite general, and designed to test hypotheses about resilience and transformation of different regional HRSs. Questions that the models could address include hypotheses about the relative role of environmental variation and variable harvest in population dynamics and resilience of wild herds, the effect of different herding objectives on resilience to environmental shocks and competition from wild herds, and whether markets and subsidies make hunting or husbandry systems more or less resilient. Testing hypotheses like these and making comparisons about resilience of regional systems requires empirically derived parameters for the models. A logical next step is, therefore, to undertake parameter estimates for the carrying capacities; the mean, variance, and autocorrelation for regional recruitment rates; and where wild and domestic herds are both found in a regional system, the parameters modeling interaction of wild and domestic herds. Time series data are not generally available to support direct statistical estimation of these parameters across different regional systems. Obtaining credible estimates would have to be indirect, likely using Bayesian inference, and subject to substantial uncertainty. Nevertheless, a well-founded empirical analysis based on the models developed here might make an important contribution to understanding resilience of these systems.

Responses to this article can be read online at: http://www.ecologyandsociety.org/issues/responses. php/5535

\section{Acknowledgments:}

The author would like to thank Konstantin Klokov for his ideas that motivated models discussed in the paper. This work was supported by the U.S. National Science Foundation (OPP 0531200).

\section{LITERATURE CITED}

Adger, W. N. 2006. Vulnerability. Global Environmental Change 16:268-281. http://dx.doi.org/10.1016/j.

gloenvcha.2006.02.006
Beach, H. 1981. Reindeer-herd management in transition: the case of Tuorpon Saameby in northern Sweden. Uppsala Studies in Cultural Anthropology 3. Almqvist and Wiksell International, Stockholm, Sweden.

Berman M., and G. Kofinas. 2004. Hunting for models: rational choice and grounded approaches to analyzing climate effects on subsistence hunting in an arctic community. Ecological Economics 49:31-46. http://dx.doi.org/10.1016/j. ecolecon.2003.12.005

Berman, M., C. Nicolson, G. Kofinas, J. Tetlichi, and S. Martin. 2004. Adaptation and sustainability in a small arctic community: results of an agent-based simulation model. Arctic $57: 401-414$.

Borgerhoff Mulder, M. 1991. Human behavioral ecology. Pages 69-98 in J. R. Krebs and N. B. Davies, editors. Behavioral ecology: an evolutionary approach. Blackwell Scientific, Oxford, UK.

Burch, E. S. Jr. 1980. Traditional Eskimo societies in northwest Alaska. Senri Ethnological Studies 4:253-304.

Burch, E. S. Jr. 1991. Herd following reconsidered. Current Anthropology 32:439-445. http://dx.doi.org/10.1086/203980

Dwyer, M. J., and K. V. Istomin. 2008. Theories of nomadic movement: a new theoretical approach for understanding the movement decisions of Nenets and Komi reindeer herders. Human Ecology 36:521-533. http://dx.doi.org/10.1007/ s10745-008-9169-2

Folke, C. 2006. Resilience: the emergence of a perspective for social-ecological systems analyses. Global Environmental Change 16:253-267. http://dx.doi.org/10.1016/j. gloenvcha.2006.04.002

Forbes, B. C., F. Stammler, T. Kumpula, N. Meschtyb, A. Pajunen, and E. Kaarlejãrvi. 2009. High resilience in the Yamal-Nenets social-ecological system, West Siberian Arctic, Russia. Proceedings of the National Academy of Sciences 106:22041-22048. http://dx.doi.org/10.1073/ pnas.0908286106

Gordon, B. 2003. Rangifer and man: an ancient relationship. Rangifer 14:15-27.

Gunderson, L. H., and C. S. Holling, editors. 2002. Panarchy: understanding transformations in human and natural systems. Island Press, Washington, D.C., USA.

Gunn, A. 2003. Voles, lemmings and caribou-population cycles revisited? Rangifer 14:105-111. http://dx.doi. org/10.7557/2.23.5.1689

Habeck, J. O. 2005. What it means to be a herdsman: the practice and image of reindeer husbandry among the Komi of northern Russia. Lit-Verlag, Münster, Germany. 
Humphries, J. E. 2007. Reindeer markets in the Circumpolar North: an economic outlook. Institute of Social and Economic Research, Anchorage, Alaska, USA. [online] URL: http:// www.iser.uaa.alaska.edu/Publications/reindeer markets jeh9-13-2007. $\underline{\mathrm{pdf}}$

Huntington, H., and H. Fox. 2005. The changing Arctic: indigenous perspectives. Pages 61-98 in C. Symon, L. Arris, and B. Heal, editors. Arctic climate impact assessment. Cambridge University Press, Cambridge, UK.

Ingold, T. 1980. Hunters, pastoralists, and ranchers: reindeer economies and their transformations. Vol. 28, Cambridge Series in Social Anthropology, Cambridge University Press. Cambridge, UK. http://dx.doi.org/10.1017/CBO9780511558047

Jansen, M., and E. Ostrom. 2006. Resilience, vulnerability, and adaptation: a cross-cutting theme of the International Human Dimensions Programme on Global Environmental Change. Global Environmental Change 16:237-239. http:// dx.doi.org/10.1016/j.gloenvcha.2006.04.003

Klokov, K. 2007. Reindeer husbandry in Russia. International Journal of Entrepreneurship and Small Business 4:726-784. http://dx.doi.org/10.1504/IJESB.2007.014981

Kofinas, G., G. Osherenko, D. Klein, and B. Forbes. 2000. Research planning in the face of change: the human role in reindeer/caribou systems. Polar Research 19:3-21. http://dx. doi.org/10.1111/j.1751-8369.2000.tb00323.x

Krupnik, I. 1993. Arctic adaptations: native whalers and reindeer herders of northern Eurasia. University Press of New England, Hannover, New Hampshire, USA.

Krupnik, I. 2000. Reindeer pastoralism in modern Siberia: research and survival in the time of crash. Polar Research 19:49-56. http://dx.doi.org/10.1111/j.1751-8369.2000.tb00327. $\underline{\mathrm{X}}$

Nelson, D. R., W. N. Adger, and K. Brown. 2007. Adaptation to environmental change: contributions of a resilience framework. Annual Review of Environment and Resources 32:395-419. http://dx.doi.org/10.1146/annurev. energy.32.051807.090348

Paine, R. 1964. Herding and husbandry: two basic concepts in the analysis of reindeer management. Folk 6:83-88.

Røed, K. H., Ø. Flagstad, M. Nieminen, Ø. Holand, M. J Dwyer, N. Røv, and C. Vilà. 2008. Genetic analyses reveal independent domestication origins of Eurasian reindeer. Proceedings of the Royal Society B 275:1849-1855. http://dx. doi.org/10.1098/rspb.2008.0332

Russell, D. E., R. G. White, and C. J. Daniel. 2005. Energetics of the Porcupine Caribou Herd: a computer simulation model. Technical Report series No. 431. Environment Canada, Canadian Wildlife Service, Ottawa, Ontario, Canada.
Thompson, D. W. J., and J. M. Wallace. 1998. The Arctic Oscillation signature in the wintertime geopotential height and temperature fields. Geophysical Research Letters 25:12971300. http://dx.doi.org/10.1029/98GL00950

Thompson, D. W. J., J. M. Wallace, and G. C. Hegerl. 1999. Annular modes in the extratropical circulation Part II: trends. Journal of Climate 13:1018-1036. http://dx.doi. org/10.1175/1520-0442(2000)013<1018:AMITEC > 2.0.CO;2

Turner, B. L., R. E. Kasperson, P. A. Matson, J. J. McCarthy, R. W. Corell, L. Christensen, N. Eckley, J. X. Kasperson, A. Luers, M. L. Martello, C. Polsky, A. Pulsipher, and A. Schiller. 2003. A framework for vulnerability analysis in sustainability sience. Proceedings of the National Academy of Sciences 100:8074-8079. http://dx.doi.org/10.1073/pnas.1231335100

Smith, E. A. 1983. Anthropological applications of optimal foraging theory: a critical review. Current Anthropology 24:625-651. http://dx.doi.org/10.1086/203066

Sahlins, M. 1972. Stone age economics. Aldine, Chicago, Illinois, USA.

Stammler, F. 2005. Reindeer nomads meet the market: culture, property and globalization at the "End of the Land". Halle Studies in the Anthropology of Eurasia. Litverlag, Berlin, Germany.

Ulvevadet, B., and K. Klokov. 2004. Family-based reindeer herding and hunting economies, and the status and management of wild reindeer/caribou populations. Centre for Saami Studies, Troms $\varnothing$, Norway.

Vitebsky, P. 2005. Reindeer people: living with animals and spirits in Siberia. HarperCollins, New York, New York, USA.

Walker, B., C. S. Holling, S. R. Carpenter, and A. Kinzig. 2004. Resilience, adaptability and transformability in socialecological systems. Ecology and Society 9(2): 5. [online] URL: http://www.ecologyandsociety.org/vol9/iss2/art5/

Ziker, J. 2002. Peoples of the tundra: native Siberians in the post communist transition. Waveland Press, Prospect Heights, Illinois, USA. 